\title{
Technostress and Its Management Techniques: A Literature Review
}

\author{
Asheka Mahboob, Tanzin Khan \\ BRAC Business School, BRAC University, Dhaka, Bangladesh \\ Email address: \\ asheka.mahboob@bracu.ac.bd (A. Mahboob), tanzin.khan@bracu.ac.bd (T. Khan) \\ To cite this article: \\ Asheka Mahboob, Tanzin Khan. Technostress and Its Management Techniques: A Literature Review. Journal of Human Resource \\ Management. Vol. 4, No. 3, 2016, pp. 28-31. doi: 10.11648/j.jhrm.20160403.12
}

Received: March 30, 2016; Accepted: April 14, 2016; Published: May 13, 2016

\begin{abstract}
Our work life effectiveness and efficiency has increased tremendously with the help of technology. But at the same time, the use of technology has increased the stress at workplace. Technostress is causing a lot of physical as well as psychological problems among workers. This paper discusses various work stressors and suggests some techniques such as stress management programs, training programs, autonomy and social support, awareness and communication to deal with work stress related problems. Literature reviews have been done to understand and suggest on this issue. However, very little work has been done on this area till now and that is why, not enough literatures could be found to gather related information. This has been a major limitation of this paper. So, there is huge scope in future to work more elaborately on the causes of technostress and how in can be handled. In this regard, cultural, socio-demographic and occupational dimensions can also be considered.
\end{abstract}

Keywords: Stress, Technostress, Technology, Productivity, Coping Mechanisms

\section{Introduction}

The workplace today is getting increasingly competitive and this demands high work pressure from employees. In this fast paced changing environment office hours have gone beyond the boundaries making work more challenging for the employees. In order to remain competitive businesses are constantly focusing on innovation and new product development, they have to focus on cost reduction and allow flexibility for adjusting with the changing environments. The increasing work demands and changing traditional work processes to a dynamic workplace subjects the employees to more stress. It seems that the organizations do not have any set hours of work or job description for the employees to follow. Moreover, the introduction of technology at work place for increasing productivity through enhanced communication via email, telephone, video conferencing etc. has added more to the stress level of employees. Several international bodies like the International Labor Organization and World Health Organization have concerns about health effects of employees due to workplace stress. Stress from work can decrease employee productivity and lower their morale. Workplace absenteeism and turnover may increase and so will workplace deviance, which in turn will lead to decreased productivity.

It is therefore, very important not only to identify the stress related problems at work but also to come up with solutions to these problems. Effective stress management technique can help to overcome the physical and psychological problems and increase productivity of the organization. In order to identify some coping mechanisms the current study has done non systematic narrative review of related literatures. From 18 literature reviews, several coping mechanisms of work stress have been identified. However, very little work has been done in the coping mechanism of stress and therefore, more detailed analysis needs to be considered in future in this area.

\section{Literature Review}

Stress has different meaning according to different discipline. As defined by Merriam Webster's Collegiate Dictionary-Stress is "a physical, chemical or emotional factor that causes bodily or mental tension". As described by Dr. Hans Selye, one of the major researchers on the concepts of stress, "stress is the rate of all wear and tear caused by life". 
Stress is defined by Moorhead and Griffin as "a person's adaptive response to a stimulus that places excessive psychological or physical demands on that person" [1].

Researchers have been contemplative over the organizational culture of modern organizations and were trying to identify different factors and phenomenon attached with this. This study aims to present a thorough literature review about the findings of various scholars about stress and its different dimensions, and management techniques.

\subsection{Causes of Stress}

Stress is related to 'job strain, tension and burnout' [15]. Emotional stress is a general expression that can range from low to high levels. It is argued that a certain level of stress increases productivity and intrapersonal development [15]. Other psychologists argue that certain level of stress help to stimulate creative thinking, motivation, personal awareness and productivity [8]. Excessive level of emotional stress can be detrimental for human health in many ways, [15]. There are many evidences to support that people's personal and environmental factors can cause mental exhaustion. Professional stress occurs when the relationships among individuals and their environmental factors are difficult to understand or rather confusing, [18]. Factors like unclear organizational structure, confusing social positions and roles, lack of empathy from colleagues and leaders are often common causes of stress, [18].

\subsection{Health Effects of Stress on Employees}

High level of occupational stress has a relation with a number of health effects namely, 'nervousness, tension, strain, anxiety and depression' [2]. If these conditions are persisted for long it can lead to heart disease and a combination of behavioral and mental instability. Early signs of stress are 'headaches, difficulty sleeping, difficulty concentrating, irritability, upset stomach and low morale', [2].

\subsection{Technostress and Its Effects on Human Health}

Technological advancement has put an added pressure to the employees. When technology is a blessing for increasing productivity, it is also one of the major causes for increasing workload of employees, [4]. Thus, the word technostress emerged and it is defined by Weil and Rosen (1997) as "our reaction to technology and how we are changing due to its influence", [1]. Another definition given by Brod (1984) is, "Technostress (computer related stress) is a combination of performance anxiety, information overload, role conflicts and organizational actors", [1]. Technostress is also metaphorically stated as an 'offspring of stress' [10].

According to Blaug, Kenyon and Lekhi (2007) people experiences workplace stress when there is an imbalance between performance expectations and resources and employee's capabilities to meet that expected performance, [10]. Another study showed that technological use at workplace has added to the occupational stress levels of employees. Their research indicates that worker's work load has increased due to introduction of technological use at the work place [6]. The most technological use at workplace is of cell phones and computers, [15]. Emails and other forms of electronic messaging like, instant messages, pagers etc. are sources of technostress too [17]. This study also mentions that cell phones and computers interfere with the personal time dimension of people's lives. Highly ambitious individuals use cell phones and computers excessively to keep up their performance and it conflicts with a positive work life balance. Since there are many organizations who pay for their employee's cell phone bills they expect employees to answer calls even in their personal time, $[11,15,17]$.

Usage of computers creates more job stresses than other forms because individuals experience fear, agitation and nervousness while they are interacting through computers [15]. This stress results from the fear of pressing a wrong key, losing information and feeling intimidated by computers, [11, 15]. Technological advancement has been rapid in the last few decades and keeping up with that pace in itself is a stress factor, [14]. The transition from manufacturing organizations to selling and finally to knowledge-based workplace have taken communication to a different level, [17]. However, even though both performance and communication have improved due to technology it has also burdened employees with information overload [5].

Technostress affects human health not only physically but also mentally. A study conducted by Joshi (2004) found that there is a correlation between the times people spend online with their level of depression, [15]. They explain that the workload because of technology has led to increasing emotional stress. SBS is a condition when a healthy individual experiences physical distress at work. SBS stands for sick building syndrome, is positively related to job stress and burnout and leads to low job satisfaction and productivity, [15].

\section{Findings and Discussion}

All the physical and mental stress needs to be addressed and effective ways to manage it needs to be identified. Among various types of job related stress, technostress is most discussed issue in today's fast paced world. Technology has made our lives easier. Job accuracy and efficiency has also increased with technological advancement. But at the same time, technology is also causing physical and mental stress. Even the type of stress caused by the use of different technologies at work place differs depending on the type of job that one is involved and responsible with.

Several coping mechanisms have been identified after literature reviews. They are stress management program, training program, autonomy and social support, awareness building among workers, acceptance of the use of technology and effective communication.

\subsection{Stress Management Program}

In a study on various types of work stress from mobile technology, it is said that the mobile technologies that is 
causing work stress in the lives of the employees can be dealt with if appropriate stress management programs can be used for each type of work that is causing stress [15]. The study identified various types of issues causing work stress and categorically suggested measures of each of the problems. Like, inappropriate keyboard and mouse use can be a cause of work stress. For that a proper posture must be maintained while working with those devices and that can ensure stress reduction from muscles, bones and tendons.

Giving too much pressure while typing can also cause stress and this also needs to be addressed. It must be ensured that one does not put too much pressure on fingers while typing [15]. The study also mentions that how we talk, what posture we take while talking for long time over phone is added to the cause of our daily work strain. We should never hold to phone on our shoulder while talking. It is also found in the study that stress that is caused by working long hours can be reduced if one takes small breaks in every 30minites [15].

So, the importance of stress management techniques should be taken seriously by organizations to avoid the increasing cost due to low productivity, high absenteeism and turnover of employees and also their claim for compensation and lawsuits [3].

\subsection{Training Programs}

Due to lack of better understanding on the negative impact of technostress at work, individuals are suffering in organizational level. But with better understanding, the workload and lack of control problem in the workplace can be dealt with and even eradicated [4, 17].

The use of training program can be an effective way to minimize stress $[4,17]$. It helps workers to learn about the benefits of using email at workplace and if a constructive email culture can be introduced there then that will reduce the stress related to email at work. Instead of just using email for communication, one can alternatively use telephone. Effective corporate and personal communication style can help to reduce the use of email that causes additional stress at work. $[4,17]$.

Another study on techno stress in workplace found that organizations need to develop stress and techno stress reduction training program to deal with this issue [1]. Six steps has been stated in his paper to combat stress caused by the use of technology. As the first step the study mentions that a workers needs to be cooperative. Then there needs to be opportunity for all for practical learning and the learnt lessons need to be distributed. The technical details that need to be used can also be simplified. Techniques should be used to lower the anxiety level and lastly priorities should be set. The study suggests that with the support of top management, this whole process can reduce work stress [1].

Teachers and students of university face psychological problems because of the demand they have from their work force [3]. Some stress management programs can be considered to deal with such problems.

\subsection{Acceptability of ICT Use}

People in teaching profession also go through tremendous stress [4]. This is because of the lack of understanding and acceptance of ICT use among them and this can be reduced if teachers start accepting the use of various technology for their work [4]. They need to start believing that this will actually make their life simpler and easier. Once the teachers adopt the ICT, half of their mental stress would be gone and they can perform in a stress free environment [4].

\subsection{Autonomy and Social Support}

A literature review on stress among prospective teachers, tried to examine the psychological problems that teacher and students of university face, A study on the impact of telework on exhaustion and job engagement also mentions that autonomy and social support can be the two ways in which our workplace stresses can be minimized [12]. One of the positive sides of telework is that there is flexibility of time that a worker can enjoy. This means that a worker can chose a time and place as per their convenience and work accordingly. But the problem is that incase of working through telework, one is never out of reach and as a result a person never gets free out of his or her work no matter where they are operating from. However, according to the study, if the person is given the autonomy to choose when top work and when not to work then that will reduce the stress level. Then if working in isolation is decreasing the moral or confidence level of an employee, if it is causing lack of communication with people then those workers should be given social support [12]. A support that can make the person feel noticed and not in isolation. Social support can also help to bring down the level of fatigue of other ICT users [11]. In the study, it is mentioned that the anxiety, skepticism and inefficiency that is created in ICT users, can be reduced if the workers get the social support. The study says that while working with ICT, the exposure to social support helps to reduce fatigue as people get to communicate and express their feelings [11].

In one study, it specifically mentions that although planning risk management and communication are some effective ways to cope with job stress, yet, social support is the most effective mechanism among them all [9].

\subsection{Create Awareness}

Another study on the factors of job stress among university teachers in Pakistan concluded that university teaching is a stressful profession in Pakistan and the problem of job stress should be managed both at individual and institutional levels. Stress can be minimized if all the staff members are aware of the causes and consequences of stress caused by their work and the university teachers are offered stress free environment [7].

\subsection{Change in Working Process and Coping Mechanism}

Some coping mechanisms of long term stress is also 
recommended in a study for the workers who work in IT sectors. According to the study, IT managers need to come up with solutions that can help them to overcome stress that are caused by their wrong practices at work [8]. The study explains that the whole working process can be done in such a manner that it will identify the causes of unnecessary stress but at the same time ensure that the job performance is also improved through the help of IT. Several steps can be followed in this regard. The first step is to assess the current situation. Then the current sources of work should be identified. After that an action plan needs to be developed that can remove unnecessary stress and can also rectify the affected performance [8]. The last step is to ensure that the IT managers come up with effective ways that can help to eliminate the barriers that is causing the stress and reducing effectiveness. A study on project managers who work in large ICT organizations, some stressors have been identified. Some coping mechanisms and its effectiveness is also discussed in the study [9]. With the help of critical incident analysis method, it is explained that there are different types of stressors and different stressors need different coping strategies.

\section{Conclusion}

Workplace working hours and excessive use of technology has increased stress among employees of different organizations. This costs organizations because high level of stress among employees leads to decreased productivity, high turnover, absenteeism and workplace deviance. Therefore, it is important that organizations must address these issues seriously and develop coping strategies to help employees deal with stress. However, it is suggested that effective training programs and top managements support helps employees to deal with stress better.

As future scope of the study, researchers must look into a comparative study of eastern and western cultural dimensions of technostress and the coping strategies to understand the effect of cultural value on stress level in different cultural perspectives. It would be also interesting to shed light on technostress experienced by different sociodemographic and occupational factors. In addition, if the research is done with quantitative data the validity and reliability of the study would be further enhanced. The results from these studies may help human resource managers of different organizations to understand the stress level from different perspective and come up with strategies for a diversified organization.

\section{References}

[1] Brillhart, P. E. (2004). Technostress in the Workplace Managing Stress in the Electronic Workplace. The Journal of American Academy of Business. Pp. 302-307.

[2] Colligan, T. W. \& Higgins, E. M. (2005). Workplace Stress: Etiology and Consequences. Journal of Workplace Behavioral Health. Vol. 21, No. 2, pp. 81-97.
[3] Gardner, S. (2010). Stress among prospective techers: a Review of the Literature. Australian Journal of Teacher Education, Vol. 35, Issue 8.

[4] Harahap, K. \& Effiyanti, T. (2015). Technostress among Educators: A Revisit of Social Cognitive Perspective. Asia Pacific Journal of Contemporary Education and Communication Technology. Vol. 1, Issue, 1.

[5] Karr-Wisniewski, P., \& Lu, Y. (2010). When More is Too Much: operationalizing Technology Overload and Exploring its Impact on Knowledge Worker Productivity. Computers in Human Behavior. Vol. 26, No. 5, pp. 1061-1072.

[6] Kayastha, R., Adhikary, P. R., \& Krishnamurthy, V. (2012). Correlates of Occupational Stress among Executives. IJRRAS. Vol. 12, pp. 101-106.

[7] Khan, A., Yusoff, R. M. D. \& Azam, K. (2014). Factors of Job Stress among university teachers in Pakistan A Conceptual Review. Journal of Management Info. Vol. 2, No. 1. Pp. 62-67

[8] Longenecker, C. O., Schaffer, C. J. \& Scazzero, J. A. (1999), Causes and consequences of stress in the IT profession.Information Systems Management, Vol. 16, Issue 3.

[9] Richmond, A. \& Skitmore, M. (2006). Stress and coping: A study of project managers in a large ICT Organization. The project management Institute, Vol. 37, No. 5, pp. 5-16.

[10] Saganuwan, M. U., Ismail, W. K. W \& Ahmad, U. N. U. (2015). Conceptual Framework: AIS Technostress and Its Effect on Professionals' Job Outcomes. Asian Social Science. Vol. 11, No. 5, pp. 97-108.

[11] Salanova, M., LIorens, S. \& Cifre, E. (2013). The Dark side of technologies: Technostress among users of information and communication technologies. International Journal of Psychology, Vol. 48, No. 3, pp. 422-436.

[12] Sardeshmukh, S. R., Sharma, D. \& Golden, T. D. (2012). Impact of Telework on Exhaustion and Job Engagement: A Job Demands and Job Resource Model. New Technology Work and Employment. Vol. 27, no. 3, PP. 193-203.

[13] Sharma, R., Jauhari, S. \& Singh, V. (2015). Stress Techniques and Management: A Review Paper. Journal of Literature, Language and Linguistics. Vol. 13, pp. 184-187.

[14] Shepherd, S. S. G. (2006). Computer Skills, Technostress, and Gender in Higher Education. Encyclopedia of Gender and Information Technology, pp. 122-128.

[15] Soylu, A. \& Campbell, S> S > (2012). Physical and Emotional Stresses of Technology on Employees in the Workplace. Journal of Employment Counseling. Vol. 49. Pp. 130-138.

[16] Sultana, N. (2011). Stress and Depression among Undergraduate Medical Students of Bangladesh. Bangladesh Journal of Medical Education. Vol. 02, Issue. 01, pp, 6-9.

[17] Taylor, H., Fieldman, G. \& Altman, Y. (2008). E-mail at Work: A Cause for Concern? The Implications of the New Communication Technologies for Health, Wellbeing and Productivity at Work. Journal of Organizational Transformation and Social Change. Vol. 5, No. 2, pp. 159-173.

[18] Vijayakumar, A. \& Remy, S. (2013). Burnout Syndrome in Library Professionals. Asian Journal of Science and Technology. Vol. 11, Issue 11., pp. 234-234. 